\title{
Magnetite $\left(\mathrm{Fe}_{3} \mathrm{O}_{4}\right)$ Heat capacity and thermodynamic properties from 5 to $350 \mathrm{~K}$, low-temperature transition
}

\author{
EDGAR F. WESTRUM, Jr. \\ Department of Chemistry, University of Michigan, Ann Arbor \\ Michigan 48104, U.S.A. \\ and \\ FREDRIK GRØNVOLD \\ Chemical Institute A, University of Oslo, Blindern \\ Oslo 3, Norway
}

(Received 3 June 1969)

\begin{abstract}
The heat capacity of synthetic $\mathrm{Fe}_{3} \mathrm{O}_{4}$ has been measured over the range from 5 to $350 \mathrm{~K}$. Values of thermodynamic functions have been calculated and $C_{p}, S^{\circ}$, and $\left(H^{\circ}-H_{0}^{\circ}\right) / T$ at $298.15 \mathrm{~K}$ are $36.04,34.93$, and $19.85 \mathrm{cal} \mathrm{mol}^{-1} \mathrm{~K}^{-1}$, respectively. In this sample the previously known $\lambda$-type transition was found to consist of two maxima, a larger one at $118.9 \mathrm{~K}$ and a smaller one at $113.3 \mathrm{~K}$, with entropy increments of $1.2 \mathrm{cal} \mathrm{mol}^{-1} \mathrm{~K}^{-1}$ and $0.2 \mathrm{cal} \mathrm{mol}^{-1} \mathrm{~K}^{-1}$, respectively. The mechanism of the transitions is discussed.
\end{abstract}

\section{Introduction}

The low-temperature heat capacity of $\mathrm{Fe}_{3} \mathrm{O}_{4}$ was measured by Parks and Kelley(1) on large natural crystals of magnetite. A marked transition presumably related to changes in the magnetic properties was observed in the temperature interval 113 to $117 \mathrm{~K}$. Millar ${ }^{(2)}$ later determined the heat capacity of magnetite over the range 60 to $300 \mathrm{~K}$ on an ore sample containing 99.0 per cent $\mathrm{Fe}_{3} \mathrm{O}_{4}$ and corrected for 0.67 per cent $\mathrm{Fe}_{2} \mathrm{O}_{3}$ and 0.37 per cent impurities (largely quartz). A pronounced heat-capacity maximum of $37.1 \mathrm{cal} \mathrm{mol}^{-1} \mathrm{~K}^{-1}$ was found at $114.15 \mathrm{~K}$. The heat-capacity measurements agreed with those of Parks and Kelley at the lowest temperatures, but were about 5.8 per cent lower at $298 \mathrm{~K}$. Calculation of the entropy gave $S(298 \mathrm{~K})=$ $(34.69 \pm 0.2) \mathrm{cal} \mathrm{mol}^{-1} \mathrm{~K}^{-1}$ in good agreement with the value 35.1 of Parks and Kelley. The anomalous change in heat capacity around $115 \mathrm{~K}$ was observed also by means of differential thermal analysis. ${ }^{(3,4)}$ More recently, the heat capacity was measured in the range 1.8 to $4.2 \mathrm{~K}$ on a natural magnetite crystal $^{(5)}$ and on synthetic samples, ${ }^{(6,7)}$ and the spin-wave contribution to the heat capacity was studied.

The fact that the observed peak in the heat capacity occurs about $5 \mathrm{~K}$ lower than the abrupt change observed in careful studies of electrical ${ }^{(8)}$ and thermal ${ }^{(9)}$ conductivity suggests the behavior to be significantly dependent upon the composition and 
purity of the magnetite and that thermophysical measurements on a sample of unambiguous purity and homogeneity are desiderata. For these reasons measurements were made on synthetically prepared $\mathrm{Fe}_{3} \mathrm{O}_{4}$. In addition, a sample of magnetite from Kiruna, Sweden, was studied, but it did not show a pronounced heat-capacity anomaly.

\section{Experimental}

\section{NATURAL MAGNETITE SAMPLE}

A sample of natural magnetite from Kiruna, Sweden, was provided from the National Museum collection by Dr. E. C. Robertson of the Geophysics Branch of the United States Geological Survey. It was a cylindrical core, $2.5 \mathrm{~cm}$ diameter by $6.2 \mathrm{~cm}$ length, diamond drilled from a hand specimen. Chemical and spectrochemical analysis indicated the following composition by mass: 0.23 per cent $\mathrm{Si}, 0.47$ per cent $\mathrm{Al}, 46.94$ per cent $\mathrm{Fe}^{3+}, 22.58$ per cent $\mathrm{Fe}^{2+}, 0.21$ per cent $\mathrm{Ca}, 0.37$ per cent $\mathrm{Mg}$, 1.37 per cent $\mathrm{Mn}^{2+}$ and 28.18 per cent $\mathrm{O}$ (by association), totalling 100.45 per cent.

The results from the measurements on the Kiruna sample are reported in the supplementary part of this paper, $\uparrow$ except for a deviation plot in figure 1 .

\section{SYNTHETIC SAMPLE}

The synthetic magnetite used in this investigation was prepared from iron(III) oxide and iron. The $\mathrm{Fe}_{2} \mathrm{O}_{3}$, "Ferrum oxydatum sec. Merck", was heated in an electric furnace at $1000^{\circ} \mathrm{C}$ until constant mass was attained. This was achieved after two $4 \mathrm{~h}$ heating periods. A small part of the sample was reduced by dry hydrogen gas at $800^{\circ} \mathrm{C}$ for $6 \mathrm{~h}$ and afterwards crushed to a fine powder. Stoichiometric proportions of this iron and the $\mathrm{Fe}_{2} \mathrm{O}_{3}$ were heated in an evacuated and sealed silica tube at $1000^{\circ} \mathrm{C}$ for 2 days and furnace-cooled.

Quantitative analysis by different investigators gave average values of 72.37 and 72.43 per cent total iron, respectively (theoretical 72.36 per cent) and 24.06 and 24.05 per cent ferrous iron (theoretical 24.12 per cent). Spectrographic analysis showed the presence of about 0.003 per cent $\mathrm{Ni}$ and $\mathrm{Si}$, and about 0.001 per cent $\mathrm{Cu}$ and Mn.

$\mathrm{X}$-ray powder photographs of the sample showed only lines from $\mathrm{Fe}_{3} \mathrm{O}_{4}$. Its lattice constant was determined at about $20^{\circ} \mathrm{C}$ in an $11.48 \mathrm{~cm}$ diameter camera with asymmetric film mounting, using iron radiation $\left[\lambda\left(\mathrm{Fe}, \mathrm{K} \alpha_{1}\right)=1.93597 \AA\right]$. The value $a=(8.3938 \pm 0.0005) \AA$ agrees within the limits of experimental error with that by Tombs and Rooksby ${ }^{(10)}$ and Abrahams and Calhoun, ${ }^{(1)} a=(8.3940 \pm 0.0005) \AA$, and is slightly smaller than that reported by Basta, ${ }^{(12)} a=(8.3963 \pm 0.0005) \AA$. For further results see reference 13 .

A specific magnetic moment determination at about $25^{\circ} \mathrm{C}$ gave $\sigma=(0.95 \pm 0.02)$ $A \mathrm{~m}^{2} \mathrm{~g}^{-1}$. This is in good agreement with the value found by $\operatorname{Gorter}^{(14)}$ and is only slightly higher than that found by Weiss and Forrer ${ }^{(15)}$ and Pauthenet. ${ }^{(16)}$

\footnotetext{
$\uparrow$ Tabulation of the heat capacity of the Kiruna sample has been deposited as NAPS document number 00630 from ASIS National Auxiliary Publications Service, c/o CCM Information Sciences, Inc., 22 West 34th Street, New York, New York 10001. A copy may be secured by citing the document number and remitting $\$ 3.00$ for photocopies or $\$ 1.00$ for microfiche in advance by check or money order payable to ASIS-NAPS.
} 


\section{CRYOGENIC TECHNIQUE}

The Mark I cryostat and the technique employed for low-temperature adiabatic calorimetry have been described elsewhere. ${ }^{(17)}$ The copper calorimeter (laboratory designation W-9) has a capacity of $90 \mathrm{~cm}^{3}$; it is gold-plated inside and out and has six vanes. The heat capacity of the empty calorimeter was determined in a separate experiment, using the same amount of indium-tin solder for sealing and Apiezon-T grease for thermal contact between calorimeter, heater, and thermometer. The heat capacity of the calorimeter-heater-thermometer assembly represented from 27 to 75 per cent of the total heat capacity observed (except in the transition region where it decreased to 8 per cent). The platinum resistance thermometer (laboratory designation A-3) has been calibrated by the National Bureau of Standards, and the temperatures are judged to correspond with the thermodynamic temperature scale within $0.1 \mathrm{~K}$ from 5 to $10 \mathrm{~K}$, within $0.03 \mathrm{~K}$ from 10 to $90 \mathrm{~K}$, and within $0.04 \mathrm{~K}$ from 90 to $350 \mathrm{~K}$. Precision is considerably better, and the temperature increments are probably correct to $0.001 \mathrm{~K}$ after corrections for quasi-adiabatic drift.

The calorimeter was loaded with sample, and helium was added (after evacuation) to provide thermal contact between sample and calorimeter. The mass of the calorimetric sample was $134.854 \mathrm{~g}$.

\section{Results}

The heat-capacity determinations are listed in table 1 in chronological order, expressed in terms of the thermochemical calorie equal to $4.184 \mathrm{~J}$. The ice point was taken to be $273.15 \mathrm{~K}$ and the relative atomic mass of iron as 55.85 . The results are presented in terms of one mole of $\mathrm{Fe}_{3} \mathrm{O}_{4}$ corresponding to $231.55 \mathrm{~g}$. An analyticallydetermined curvature correction was applied to the observed values of $\Delta H / \Delta T$. The approximate temperature increments can usually be inferred from the adjacent mean temperatures in table 1.

The heat-capacity versus temperature curve is shown in figure 1 and transitions are seen to occur near $116 \mathrm{~K}$. A smaller peak is observed at $113.3 \mathrm{~K}$ and a larger one at $118.9 \mathrm{~K}$. Except for the double peak, the results resemble those found earlier by Parks and Kelley ${ }^{(1)}$ and by Millar ${ }^{(2)}$ over the common region (see deviation plot in figure 1).

Values of $C_{p}, S^{\circ}-S_{0}^{\circ}$, and $\left(H^{\circ}-H_{0}^{\circ}\right) / T$ for $\mathrm{Fe}_{3} \mathrm{O}_{4}$ are listed at selected temperatures in table 2. The Gibbs energy function values are not given because of uncertainty concerning the zero-point entropy of magnetite. The enthalpy and entropy increments were calculated by numerical integration of the heat-capacity values which are considered to have a probable error of about 5 per cent at $5 \mathrm{~K}, 1$ per cent at $10 \mathrm{~K}$, and 0.1 per cent above $25 \mathrm{~K}$. Values below $5 \mathrm{~K}$ are extrapolated using the Debye $T^{3}$ limiting law. The effects of nuclear spin and isotopic mixing are not included in the entropies. The estimated probable error in the thermodynamic functions is 0.1 per cent above $100 \mathrm{~K}$, but some of the results are given to an additional digit because of their significance on a relative basis. 
TABLE 1 . Heat capacity of synthetic magnetite $\left(\mathrm{Fe}_{3} \mathrm{O}_{4}\right)^{a}$

\begin{tabular}{|c|c|c|c|c|c|}
\hline$\frac{T}{\mathbf{K}}$ & $\frac{C_{p}}{\mathrm{cal} \mathrm{mol} \mathrm{m}^{-1} \mathrm{~K}^{-1}}$ & $\frac{T}{\mathbf{K}}$ & $\frac{C_{p}}{\text { cal mol }{ }^{-1} \mathrm{~K}^{-1}}$ & $\frac{T}{\mathrm{~K}}$ & $\frac{C_{p}}{\text { cal } \mathrm{mol}^{-1} \mathrm{~K}^{-1}}$ \\
\hline \multicolumn{2}{|c|}{ Series I } & $\begin{array}{l}101.86 \\
106.64\end{array}$ & $\begin{array}{l}13.473 \\
14.590\end{array}$ & \multicolumn{2}{|c|}{ Series III } \\
\hline 66.61 & 6.432 & 108.15 & 15.00 & 112.97 & 28.34 \\
\hline 72.42 & 7.500 & 109.64 & 15.44 & 113.33 & 33.2 \\
\hline 78.49 & 8.667 & 111.08 & 15.97 & 113.65 & 31.5 \\
\hline 85.23 & 10.025 & 112.41 & 19.72 & 114.00 & 29.7 \\
\hline 92.23 & 11.438 & 113.46 & 32.0 & 114.36 & 29.0 \\
\hline 99.66 & 12.984 & 114.38 & 28.9 & 114.74 & 28.4 \\
\hline 107.65 & 14.275 & 115.35 & 29.2 & 115.12 & 28.5 \\
\hline 114.65 & 28.83 & 116.29 & 30.7 & 115.49 & 29.6 \\
\hline 120.08 & 32.15 & 117.16 & 33.7 & 115.85 & 30.4 \\
\hline \multirow[t]{2}{*}{126.57} & 18.58 & 117.95 & 42.2 & 116.19 & 30.7 \\
\hline & & 118.63 & 50.2 & 116.57 & 28.8 \\
\hline \multirow{2}{*}{\multicolumn{2}{|c|}{ Series II }} & 119.27 & 47.3 & 116.99 & 31.7 \\
\hline & & 120.02 & 30.8 & 117.31 & 35.1 \\
\hline 6.49 & 0.0056 & 121.04 & 20.1 & 117.61 & 38.2 \\
\hline 7.67 & 0.0099 & 122.26 & 18.37 & 117.90 & 40.7 \\
\hline 8.55 & 0.0150 & 123.54 & 18.26 & 118.09 & 41.4 \\
\hline 9.65 & 0.0235 & 125.17 & 18.14 & 118.18 & 43.1 \\
\hline 10.56 & 0.0336 & 128.50 & 18.82 & 118.27 & 42.1 \\
\hline 11.64 & 0.0494 & 133.01 & 19.48 & 118.36 & 45.5 \\
\hline 13.01 & 0.0758 & 139.39 & 20.42 & 118.44 & 46.9 \\
\hline 14.33 & 0.0904 & 148.82 & 21.73 & 118.53 & 47.7 \\
\hline 15.71 & 0.1145 & 159.81 & 23.19 & 118.62 & 48.2 \\
\hline 17.15 & 0.1466 & 170.09 & 24.48 & 118.69 & 42.0 \\
\hline 18.68 & 0.1974 & 179.53 & 25.60 & 118.77 & 52.4 \\
\hline 20.36 & 0.2619 & 188.38 & 26.62 & 118.88 & 117.0 \\
\hline 20.76 & 0.2766 & 197.14 & 27.57 & 118.93 & 52.3 \\
\hline 22.87 & 0.3843 & 202.99 & 28.12 & 119.01 & 50.2 \\
\hline 24.02 & 0.4547 & 211.81 & 29.07 & 119.10 & 49.8 \\
\hline 26.01 & 0.5868 & 220.86 & 29.95 & 119.18 & 48.8 \\
\hline 27.98 & 0.7444 & 230.12 & 30.83 & 119.26 & 44.9 \\
\hline 30.26 & 0.9502 & 239.24 & 31.54 & 119.35 & 44.8 \\
\hline 33.06 & 1.253 & 248.52 & 32.38 & 119.44 & 43.3 \\
\hline 36.57 & 1.643 & 257.89 & 33.19 & 119.55 & 41.7 \\
\hline 40.74 & 2.183 & 267.11 & 33.83 & 119.81 & 37.1 \\
\hline 45.24 & 2.827 & 276.17 & 34.50 & 120.12 & 28.6 \\
\hline 50.02 & 3.561 & 285.24 & 35.18 & 120.51 & 22.84 \\
\hline 55.14 & 4.397 & 294.51 & 35.80 & 120.95 & 19.98 \\
\hline 60.69 & 5.351 & 303.96 & 36.21 & 121.42 & 19.15 \\
\hline 67.29 & 6.556 & 313.44 & 37.00 & 121.88 & 18.62 \\
\hline 73.24 & 7.650 & 322.91 & 37.57 & 122.35 & 18.24 \\
\hline 79.81 & 8.927 & 332.59 & 38.14 & 122.83 & 18.22 \\
\hline 86.49 & 10.337 & 341.64 & 38.64 & 123.31 & 18.02 \\
\hline 94.07 & 11.901 & 347.94 & 38.98 & & \\
\hline
\end{tabular}


TABLE 2. Thermodynamic properties of synthetic magnetite $\left(\mathrm{Fe}_{3} \mathrm{O}_{4}\right)^{a}$

\begin{tabular}{|c|c|c|c|}
\hline$T$ & $C_{p}$ & $S^{\circ}$ & $\left(H^{\circ}-H_{0}^{\circ}\right) / T$ \\
\hline $\bar{K}$ & cal mol ${ }^{-1} \mathbf{K}^{-1}$ & cal mol-1 $\mathrm{K}^{-1}$ & $\mathrm{cal} \mathrm{mol}{ }^{-1} \mathrm{~K}^{-1}$ \\
\hline 10 & 0.027 & 0.010 & 0.006 \\
\hline 15 & 0.101 & 0.034 & 0.025 \\
\hline 20 & 0.247 & 0.080 & 0.059 \\
\hline 25 & 0.517 & 0.162 & 0.122 \\
\hline 30 & 0.928 & 0.290 & 0.220 \\
\hline 35 & 1.460 & 0.472 & 0.358 \\
\hline 40 & 2.082 & 0.707 & 0.534 \\
\hline 45 & 2.789 & 0.992 & 0.745 \\
\hline 50 & 3.558 & 1.326 & 0.987 \\
\hline 60 & 5.231 & 2.119 & 1.553 \\
\hline 70 & 7.045 & 3.062 & 2.207 \\
\hline 80 & 8.962 & 4.126 & 2.930 \\
\hline 90 & 10.984 & 5.298 & 3.712 \\
\hline 100 & 13.063 & 6.561 & 4.542 \\
\hline 110 & 15.517 & 7.912 & 5.424 \\
\hline 120 & $(32.5)$ & 10.535 & 7.498 \\
\hline 130 & 19.02 & 12.065 & 8.391 \\
\hline 140 & 20.51 & 13.529 & 9.203 \\
\hline 150 & 21.89 & 14.992 & 10.003 \\
\hline 160 & 23.21 & 16.447 & 10.788 \\
\hline 170 & 24.47 & 17.892 & 11.556 \\
\hline 180 & 25.66 & 19.325 & 12.307 \\
\hline 190 & 26.80 & 20.743 & 13.040 \\
\hline 200 & 27.87 & 22.145 & 13.755 \\
\hline 210 & 28.90 & 23.530 & 14.451 \\
\hline 220 & 29.86 & 24.897 & 14.675 \\
\hline 230 & 30.78 & 26.245 & 15.791 \\
\hline 240 & 31.66 & 27.574 & 16.434 \\
\hline 250 & 32.50 & 28.884 & 17.060 \\
\hline 260 & 33.31 & 30.174 & 17.670 \\
\hline 270 & 34.08 & 31.446 & 18.263 \\
\hline 280 & 34.81 & 32.699 & 18.841 \\
\hline 290 & 35.50 & 33.932 & 19.404 \\
\hline 300 & 36.16 & 35.147 & 19.951 \\
\hline 350 & 39.11 & 40.948 & 22,483 \\
\hline 273.15 & 34.31 & 31.84 & 18.45 \\
\hline 298.15 & 36.04 & 34.93 & 19.85 \\
\hline
\end{tabular}

${ }^{a} 1 \mathrm{cal}=4.184 \mathrm{~J} ; 1 \mathrm{~mol} \mathrm{Fe} \mathrm{O}_{4} \triangleq 231.55 \mathrm{~g}$. 


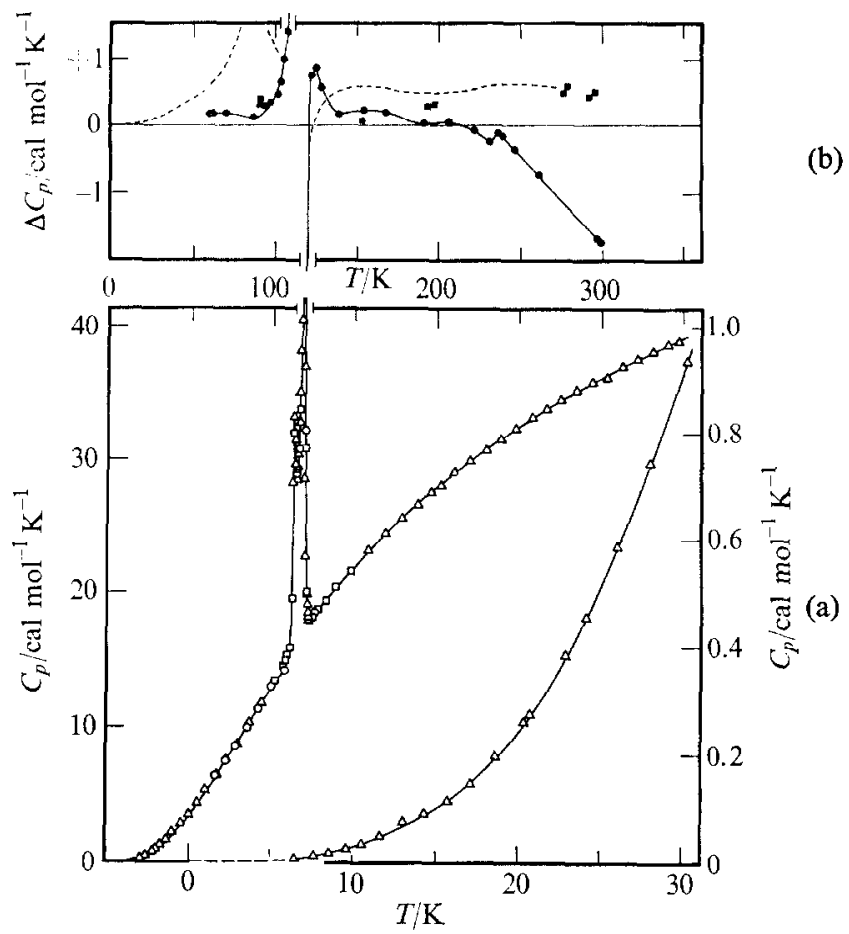

FIGURE 1. (a) Heat capacity of magnetite. $O$ represents series I, $\square$ represents series II, $\Delta$ represents series III. (b) Deviation plot of other measurements from the present ones on synthetic magnetite. represents results of Parks and Kelley, ${ }^{(1)}-$ represents results of Millar, ${ }^{(2)} \ldots \ldots$ represents results on Kiruna magnetite.

\section{GENERAL}

\section{Discussion}

The present heat-capacity results are from 0.4 to 3.6 per cent lower than those of Parks and Kelley ${ }^{(1)}$ which accounts for the lower observed entropy at $298.15 \mathrm{~K}$, $34.93 \mathrm{cal} \mathrm{mol}^{-1} \mathrm{~K}^{-1}$ against $35.1 \mathrm{cal} \mathrm{mol}^{-1} \mathrm{~K}^{-1}$. The results of $\mathrm{Millar}^{(2)}$ are about 3 per cent higher at the lowest temperatures, but are about 5 per cent lower at the highest temperatures. His calculated entropy was $34.69 \mathrm{cal} \mathrm{mol}^{-1} \mathrm{~K}^{-1}$, or slightly lower than the value found here. The enthalpy increments of magnetite above room temperature have most recently been measured by Coughlin et al. ${ }^{(18)}$ The derived linear heat-capacity curve crosses the present results at $315 \mathrm{~K}$ at only a slight angle; the results are thus in reasonable accord.

An enlarged plot of the heat capacity in the region of low-temperature transition is shown in figure 2 . The maximum at $118.88 \mathrm{~K}$ is very close to the transition temperature $(119.4 \mathrm{~K})$ found by Calhoun, ${ }^{(8)}$ while the lower peak lies close to Millar's ${ }^{(2)}$ transition temperature.

There are no indications of a bifurcated peak in earlier studies.

Several hypotheses can be advanced in explanation of the double peak. For example, only a slight variation of the $\mathrm{Fe}^{2+} / \mathrm{Fe}^{3+}$ ratio is obviously enough to affect the 


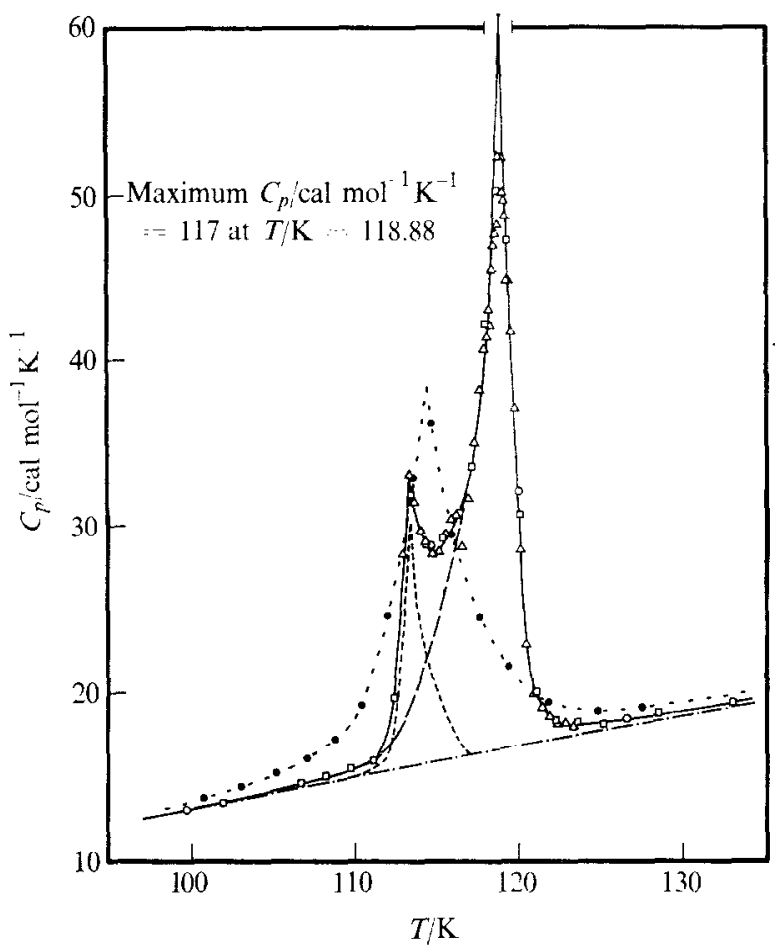

FIGURE 2. Heat capacity of magnetite in the transition region. $\bigcirc$ represents series $I, \square$ represents series II, $\triangle$ represents series III. - -0 - represents data by Millar, ${ }^{(2)} \ldots .-.-$ represents estimated lattice heat capacity, - - - represents resolution of lower temperature peak, _ _ _ represents resolution of higher temperature peak.

nature of the transition. This was clearly demonstrated by the change in temperature dependence of the electrical conductivity ${ }^{(19)}$ on synthetic samples with slightly different oxygen content. Characteristic changes in magneto-crystalline anisotropy ${ }^{(20)}$ and acoustic-loss peaks ${ }^{(21)}$ also result from small variations in oxygen content. Impurities have an equally detrimental effect on the transition as demonstrated by heat-capacity measurements on the natural magnetite crystal from Kiruna, Sweden, as well as by numerous studies reported in the literature. It is, however, considered unlikely that the double peak is due to impurities in the sample or to the fact that it was heated in a silica tube, since the spectrographic analysis showed the presence of less than 0.01 per cent metallic impurities (including silicon). Gross inhomogeneity (or phase separation) in the sample might account for the behavior. It is known ${ }^{(22)}$ that the $\mathrm{Fe}_{3} \mathrm{O}_{4}$-phase has a considerable range of homogeneity, extending between the limits $\mathrm{FeO}_{1.333}$ and $\mathrm{FeO}_{1.382}$ at $1457^{\circ} \mathrm{C}$. What happens to this solid solution on cooling under non-equilibrium conditions has not yet been studied in detail, but it is conceivable that phases with slightly different composition and structure might be formed, as in the $\mathrm{VO}_{2-x}{ }^{(23)}$ and $\mathrm{TiO}_{2-x}{ }^{(24)}$ systems. Until evidence confirming these or other explanations is available, the double maximum in the heat-capacity curve 
is considered to be a property of $\mathrm{Fe}_{3} \mathrm{O}_{4}$. Other relevant information concerning the transition region will now be introduced. The discussions will be limited to some simple property changes. The large body of cross-related effects, i.e. thermoelectric, magneto-caloric, magneto-electric, etc., will not be considered.

\section{STRUCTURAL ASPECTS}

After the atomic coordinates in crystalline magnetite near $300 \mathrm{~K}$ had been refined by X-ray diffraction methods, ${ }^{(25)}$ Verwey and De Boer ${ }^{(26)}$ concluded that $\mathrm{Fe}_{3} \mathrm{O}_{4}$ has an inverse-spinel-type structure with $\mathrm{Fe}^{2+}$ and $\mathrm{Fe}^{3+}$ ions distributed at random over the octahedral positions. Subsequently, Verwey ${ }^{(19)}$ inferred that the transition phenomenon involves an order-disorder effect on the ions at the octahedral positions. Below the transition temperature the ferrous and ferric ions form mutually perpendicular rows parallel to $(001)$. The structure was assumed to have tetragonal symmetry ${ }^{(27)}$ although orthorhombic symmetry ${ }^{(28)}$ would be more appropriate. $\mathrm{X}$-ray powder photographs of magnetite below the transition temperature were interpreted in terms of a rhombohedral unit cell, ${ }^{(10,29)}$ while other authors ${ }^{(11,30)}$ claimed that it was orthorhombic. Symmetry considerations ${ }^{(31)}$ show that transition from the reported orthorhombic structure to the cubic one is possible only as a first-order transition and not as a higher-order transition.

No conclusion regarding the distribution of $\mathrm{Fe}^{2+}$ and $\mathrm{Fe}^{3+}$ ions among the tetrahedral and octahedral lattice sites could be drawn on the basis of X-ray data, but Néel ${ }^{(32)}$ interpreted the magnetic data on magnetite by assuming antiferromagnetic coupling between the spin moments of the $\mathrm{Fe}^{3+}$ ions on $\mathrm{A}$-sites and the $\mathrm{Fe}^{2+}$ and $\mathrm{Fe}^{3+}$ ions on B-sites. This antiferromagnetic arrangement was strongly supported by neutron diffraction work on magnetite powder by Shull et al. ${ }^{(33)}$ Further neutron diffraction work by Hamilton ${ }^{(34)}$ on synthetic crystals gave a convincing confirmation of the Verwey order scheme. Recent neutron diffraction work ${ }^{(35)}$ has shown the presence of extra reflexions below the transition which are attributed to a doubling of the $c$-axis. In a natural crystal these reflections disappeared gradually between 100 and $120 \mathrm{~K}$, while for a synthetic crystal they vanished abruptly at $(118.5 \pm 1) \mathrm{K}$. Thus, there are indications of complex structural behavior of magnetite in the transition region and of a continuous transition being precluded by symmetry conditions. The presence of an intermediate structure which can accommodate increasing disorder, therefore, seems plausible.

\section{ELECTRICAL ASPECTS}

The high electrical conductivity of magnetite was rationalized ${ }^{(36,37)}$ in terms of random distribution of $\mathrm{Fe}^{2+}$ and $\mathrm{Fe}^{3+}$ ions over equivalent lattice positions. As the temperature is lowered a sudden decrease in conductivity is observed. ${ }^{(3,6,38)}$ In stoichiometric synthetic single crystals the transition is reported ${ }^{(6)}$ to take place at $(119.4 \pm 0.3) \mathrm{K}$, and it is marked by the conductivity dropping by a factor of 90 within a temperature interval of about $1 \mathrm{~K}$. The conductivity is anisotropic below the transition, as also noted earlier. ${ }^{(27)}$

Hall effect and thermal e.m.f. measurements have led to the conclusion ${ }^{(39)}$ that the electrical conductivity of stoichiometric $\mathrm{Fe}_{3} \mathrm{O}_{4}$ is of electronic origin. Theoretical 
considerations ${ }^{(40)}$ are in agreement with a hopping electron model above the transition, and a thermally-activated hopping mechanism involving a fairly complex defect below the transition. ${ }^{(4)}$ The transition is considered ${ }^{(42)}$ to be of the MottWigner type in which the low-density insulating state is brought about by electron correlation. The pressure dependence of the conductivity ${ }^{(43)}$ is consistent with such a model.

The temperature dependence of the electrical resistivity in magnetic fields was reported $^{(44)}$ and found to show two minima, one at $111.5 \mathrm{~K}$ and the other at $95 \mathrm{~K}$, presumably due to the dispersion of electrons over fluctuations in magnetization and density, respectively.

Characteristic anomalies in the thermoelectric and Nernst-Ettingshausen effects in the low-temperature transition region were taken ${ }^{(45)}$ to indicate a reorganization of the energy spectrum of the conductivity electrons in magnetite.

\section{MAGNETIC ASPECTS}

The magnetic properties of magnetite samples were measured by Weiss and Forrer ${ }^{(15)}$ and the highest magnetization values found to be associated with the stoichiometric composition $\mathrm{Fe}_{3} \mathrm{O}_{4}$. At $120 \mathrm{~K}$ a transition was observed which, however, did not affect its magnetic moment (i.e., $4.07 \mathrm{Bohr}$ magnetons per molecule of $\mathrm{Fe}_{3} \mathrm{O}_{4}$ extrapolated to $0 \mathrm{~K}$ ). The small variation in electrical conductivity with magnetic field strength $^{(46-48)}$ is in keeping with the view that the spontaneous magnetization does not change during the transition. The low moment was explained by the Néel theory of ferrimagnetism ${ }^{(32)}$ on the assumption that the magnetic moments of the $\mathrm{Fe}^{3+}$ ions are mutually annihilated by antiferromagnetic coupling. On the basis of magnetization, ${ }^{(49,50)}$ thermal expansion, and magnetostriction ${ }^{(51)}$ measurements, the possible origin of the magnetic anistropy below the transition is discussed. ${ }^{(52)}$ Additional results from magnetostriction, ${ }^{(53)}$ hysteresis loop and strain gauge measurements, ${ }^{(54,55)}$ and magnetic torque curves ${ }^{(56-60)}$ established the structure below the transition as orthorhombic, and magnetic anistropy constants were derived.

In contrast to the results of an earlier calculation, ${ }^{(61)}$ Slonczewski ${ }^{(62)}$ finds that the calculated anistropy constants $\left(K_{a}=-1.2 \mathrm{~J} \mathrm{~cm}^{-3}, K_{b}=1.2 \mathrm{~J} \mathrm{~cm}^{-3}\right)$ disagree with the experimental values $\left(K_{a} \approx 0.05 \mathrm{~J} \mathrm{~cm}^{-3}, K_{b} \approx 0.05 \mathrm{~J} \mathrm{~cm}^{-3}\right)$ both with regard to order of magnitude and direction of easy magnetization. The presence of disorder might, however, account for the discrepancy.

Ferrimagnetic-resonance results ${ }^{(28,63,64)}$ have been interpreted in terms of domain structures $^{(65)}$ and twinning ${ }^{(8,64)}$ and separate contributions from the ferric ions at octahedral and tetrahedral sites. ${ }^{(66)}$ The discrepancy between the $g$-factor obtained by this method and nuclear magnetic resonance studies ${ }^{(67,68)}$ suggests that some unexplained effect obscures the ferrimagnetic resonance results. ${ }^{(69)}$

Mössbauer absorption spectra ${ }^{(70-73)}$ differ in detail. They are interpreted in terms of electron hopping among the octahedral $\mathrm{Fe}^{2+}$ and $\mathrm{Fe}^{3+}$ ions at $300 \mathrm{~K}$, which produces an averaged spectrum clearly distinguishable from that of the tetrahedral $\mathrm{Fe}^{3+}$ ions. At $77 \mathrm{~K}$, where the hopping has ceased, the three kinds of ions should show their separable spectra, but no difference between the two types of $\mathrm{Fe}^{3+}$ ions could be observed. This can be understood ${ }^{(69)}$ on the assumption that the hyperfine 
field at the $\mathrm{Fe}^{3+}$ nucleus is the same on octahedral and tetrahedral sites-apart from the sublattice magnetization, which in this case is probably also equal-since the spin quantum numbers are the same $(S=5 / 2)$.

\section{THERMODYNAMIC ASPECTS}

The enthalpy and entropy increments associated with the transition were evaluated by subtracting the lattice contribution from the total increments in the range 100 to $140 \mathrm{~K}$. The lattice heat-capacity values were estimated on the basis of a gradual change in Debye $\Theta$ 's with temperature from $\Theta / \mathrm{K}=550$ at $100 \mathrm{~K}$ to 571 at $140 \mathrm{~K}$ (see figure 2). The results are given in table 3 . The total entropy increment observed, $1.35 \mathrm{cal} \mathrm{mol}^{-1} \mathrm{~K}^{-1}$, agrees well with the value $1.3 \mathrm{cal} \mathrm{mol}^{-1} \mathrm{~K}^{-1}$ estimated from Parks and Kelley's '(1) results as $\Delta H / \Delta T$ for $T=115 \mathrm{~K}$, and the value $1.05 \mathrm{cal} \mathrm{mol}^{-1}$ $\mathrm{K}^{-1}$ evaluated graphically from Millar's ${ }^{(2)}$ results.

TABLE 3. Enthalpy and entropy of transition in magnetite ${ }^{a}$

\begin{tabular}{|c|c|c|c|c|c|c|}
\hline & Series & $\frac{T_{1}}{\mathrm{~K}}$ & $\frac{T_{2}}{\mathbf{K}}$ & $\frac{H\left(T_{2}\right)-H\left(T_{1}\right)}{\mathrm{cal} \mathrm{mol}^{-1}}$ & \multicolumn{2}{|c|}{$\frac{H(125 \mathrm{~K})-H(110 \mathrm{~K})}{\mathrm{cal} \mathrm{mol}^{-1}}$} \\
\hline I & $7-10$ & 103.515 & 130.500 & 598.59 & & 402.0 \\
\hline IV & 130 & 109.884 & 124.245 & 388.51 & & 400.4 \\
\hline V & 131 & 110.023 & 124.847 & 397.46 & & 400.5 \\
\hline VI & 132 & 110.036 & 129.060 & 477.55 & & 402.3 \\
\hline VII & 133 & 110.081 & 125.113 & 401.95 & & 401.2 \\
\hline \multirow{7}{*}{ VIII } & 134 & 109.758 & 124.959 & 404.71 & & 401.7 \\
\hline & & \multicolumn{3}{|c|}{ Mean value $H(125 \mathrm{~K})-H(110 \mathrm{~K})$} & $=$ & 401.3 \\
\hline & & \multicolumn{3}{|c|}{ - Lattice contribution $H(125 \mathrm{~K})-H(110 \mathrm{~K})$} & $=$ & -246.3 \\
\hline & & \multirow{2}{*}{\multicolumn{4}{|c|}{+ Excess below $110 \mathrm{~K} \Delta\{H(110 \mathrm{~K})-H(100 \mathrm{~K})\}=$}} & 155 \\
\hline & & & & & & 1 \\
\hline & & \multicolumn{4}{|c|}{+ Excess above $125 \mathrm{~K} \Delta\{H(140 \mathrm{~K})-H(125 \mathrm{~K})\}=$} & 2 \\
\hline & & \multicolumn{3}{|c|}{$\begin{array}{l}\text { Enthalpy of transition } \Delta H_{\mathrm{t}} \\
\text { Entropy of transition } \Delta S_{\mathrm{t}}=1.35 \mathrm{cal} \mathrm{mol}^{-1} \mathrm{~K}^{-1}\end{array}$} & $=$ & 158 \\
\hline
\end{tabular}

${ }^{a} 1 \mathrm{cal}=4.184 \mathrm{~J} ; 1 \mathrm{~mol} \mathrm{Fe}_{3} \mathrm{O}_{4} \cong 231.55 \mathrm{~g}$.

Resolution of the heat-capacity peaks into their components is rather difficult, and cannot be done by ascribing the same shape to both of them. In fact, the pre-transition effects associated with the higher-temperature peak appear to extend below the onset of the lower-temperature transition. The latter-may involve a phase transition from the orthorhombic to an intermediate structure (with an entropy increment of only about $0.2 \mathrm{cal} \mathrm{mol}^{-1} \mathrm{~K}^{-1}$ ), related to a change in crystal structure upon onset of long-range disorder of the $\mathrm{Fe}^{2+}$ and $\mathrm{Fe}^{3+}$ ion distribution.

As discussed by Anderson ${ }^{(74)}$ the octahedral lattice sites in the spinel structure form an arrangement for which it is possible to achieve essentially perfect shortrange order while maintaining a finite entropy. The sites can be described in terms of 
tetrahedra arranged on a diamond lattice and connected at their apices. Each site is presumably occupied by one of two kinds of iron atoms present in equal numbers. We are concerned with changes in their distribution with temperature, and with residual disorder. Questions also arise with regard to the physical difference between the two kinds of atoms, and how they interconvert.

The available evidence indicates that the magnetic moment of magnetite does not change during the transition. Thus the characteristic difference between the atoms on the octahedral sites in this context is that half of them possess five unpaired $3 \mathrm{~d}$ electrons and the other half four unpaired electrons and one unshared pair. The order-disorder process therefore involves distribution of $(N / 2)$ localized $3 \mathrm{~d}$ electrons over $N$ atoms. The process by which this takes place has not been clarified in detail; it conceivably involves both valence and conduction electrons. Calculations of the coulombic order energy ${ }^{(75-78)}$ in $\mathrm{Fe}_{3} \mathrm{O}_{4}$ yields $39.3 \mathrm{kcal} \mathrm{mol}^{-1}$ and indicates that considerable short-range order is present above the transition. Anderson ${ }^{(74)}$ suggests that the short-range order might be discussed as one in which there is a maximum number of $\mathrm{Fe}^{2+}-\mathrm{Fe}^{3+}$ pairs; i.e. two $\mathrm{Fe}^{2+}$ and two $\mathrm{Fe}^{3+}$ ions are present on each tetrahedron.

Assuming nearest-neighbor interactions only, one can find a number of configurations, all of which have the lowest possible energy. Long-range coulombic forces are only 5 per cent effective in creating long-range order. More recently a general expression for the correlation function was obtained. ${ }^{(79)}$ Under simplified conditions the energy decrement between the Anderson short-range ordered and the Verwey structures was calculated to be only 3.8 per cent. Complete ordering might not be achieved, therefore, on cooling magnetite through the transition region.

The residual or zero-point entropy might be estimated in a manner similar to that employed by Pauling ${ }^{(80)}$ for ice. The resulting lower limit for one mole of $\mathrm{Fe}_{3} \mathrm{O}_{4}$ is

$$
S_{0}=0.81 \mathrm{cal} \mathrm{mol}^{-1} \mathrm{~K}^{-1} \text {. }
$$

The expected entropy change from complete order to complete disorder is equal to $2 R \ln 2$ per mole $\mathrm{Fe}_{3} \mathrm{O}_{4}$, i.e. $2.75 \mathrm{cal} \mathrm{mol}^{-1} \mathrm{~K}^{-1}$, while the actually observed value is only $1.35 \mathrm{cal} \mathrm{mol}^{-1} \mathrm{~K}^{-1}$. Some part of the difference is presumably due to residual entropy below the transition, and some to short-range order persisting above the transition. A different view on the transition is adopted by de Bergevin and Brunel. ${ }^{(81)}$ They suggest that Slater's model ${ }^{(82)}$ for the ferroelectric transition in potassium dihydrogenphosphate is applicable to the transition in magnetite and conclude that it involves change from complete long-range order to short-range order with an entropy increment

$$
\Delta S_{\mathrm{t}}=0.78 \mathrm{cal} \mathrm{mol}^{-1} \mathrm{~K}^{-1} \text {. }
$$

In the high-temperature limit the disorder entropy is reported to be $0.81 \mathrm{cal} \mathrm{mol}^{-1}$ $\mathrm{K}^{-1}$. These entropy values are, however, only about half of that observed here and cast doubt upon the applicability of the model.

The possible existence of zero-point entropy in magnetite needs further verification from combination of thermal and equilibrium data for suitable reactions. One such reaction is

$$
3 \mathrm{Fe}(\mathrm{s})+4 \mathrm{H}_{2} \mathrm{O}(\mathrm{g})=\mathrm{Fe}_{3} \mathrm{O}_{4}(\mathrm{~s})+4 \mathrm{H}_{2}(\mathrm{~g}) \text {, }
$$


for which equilibrium results exist and thermal results are precisely known except for the heat capacity of $\mathrm{Fe}_{3} \mathrm{O}_{4}$ above $350 \mathrm{~K}$. Such measurements are in progress. Upon completion, the problem can then be reconsidered.

\section{SPIN WAVE CONTRIBUTIONS}

The effect of elementary excitations of the spin system of inverse spinels has been considered by Kouvel ${ }^{(83)}$ and shown to occasion an $\alpha T^{3 / 2}$ contribution to the heat capacity at very low temperatures in addition to the Debye $\beta T^{3}$ lattice term. Heatcapacity measurements by $\mathrm{Kouvel}^{(5)}$ in the range 1.2 to $4.2 \mathrm{~K}$ indicated a much higher spin-wave contribution than is consistent with theory. Results on ironsubstituted nickel ferrites ${ }^{(84)}\left(\mathrm{Ni}_{x} \mathrm{Fe}_{2}+\mathrm{O}_{4}\right.$ with $x=1.0,0.88$, and 0.58$)$ also indicate a high value for magnetite. Later measurements by Dixon et al. ${ }^{(7)}$ over the same region are considcrably lower, but not as low as required by theory. Our values over the 5 to $10 \mathrm{~K}$ region are plotted as $C T^{-3 / 2}$ versus $T^{3 / 2}$ in figure 3 together with the earlier results. They are in accord within experimental error with those by Dixon et al. ${ }^{(7)}$

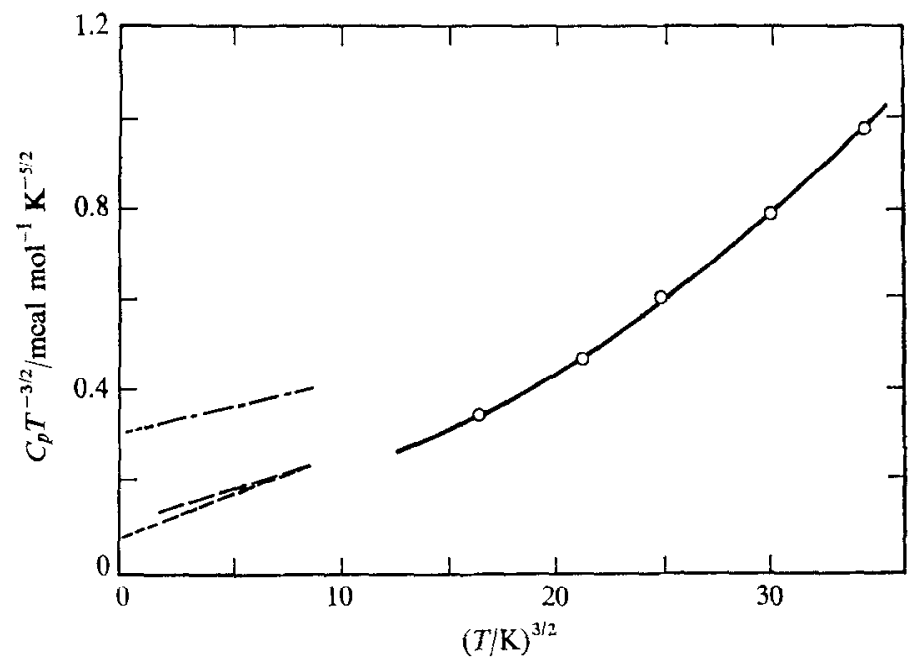

FIGURE 3. Spin-wave contributions to the heat capacity of magnetite. $-\mathrm{O}-\mathrm{O}-$ represents experimental results on synthetic magnetite, and - - represents two series of results of Dixon et al $^{(7)}-. \cdots .-$ represents results of Kouvel, ${ }^{(5)}$

According to Kouvel ${ }^{(83)}$ the spin-wave heat capacity in the absence of long-range order on the octahedral site is

$$
C_{m}=0.113\left\{\frac{\left(2 S_{\mathrm{B}}-S_{\mathrm{A}}\right) k T}{-(11 / 2) J_{\mathrm{AB}} S_{\mathrm{A}} S_{\mathrm{B}}+J_{\mathrm{AA}} S_{\mathrm{A}}^{2}+2 J_{\mathrm{BB}} S_{\mathrm{B}}^{2}}\right\}^{3 / 2}
$$

where $S_{\mathrm{A}}$ and $S_{\mathrm{B}}$ are the spin quantum numbers $S_{\mathrm{A}}=5 / 2$ and $S_{\mathrm{B}}=(1 / 2)(5 / 2+4 / 2)=$ $9 / 4$, respectively; $J_{\mathrm{AA}}, J_{\mathrm{AB}}$, and $J_{\mathrm{BB}}$ are exchange integral values for the $\mathrm{AA}, \mathrm{AB}$, and $\mathrm{BB}$ interactions. According to Néel, ${ }^{(32)}$ all the interchange interactions in ferrites are antiferromagnetic and $J_{\mathrm{AB}} \gg J_{\mathrm{AA}}$ or $J_{\mathrm{BB}}$ as a result of the relative magnitudes of the superexchange. 
Spin-wave dispersion relations for magnetite have been derived ${ }^{(69,85-89)}$ and dispersion curves obtained by inelastic neutron scattering techniques above the transition $^{(90-93)}$ and below. ${ }^{(94,95)}$

In the earlier work only $J_{\mathrm{AB}}$ was considered while the most recent evaluation ${ }^{(96)}$ leads to $J_{\mathrm{AA}}=(-1.52 \pm 0.46) \mathrm{meV}, J_{\mathrm{AB}}=(-2.42 \pm 0.04) \mathrm{meV}$, and $J_{\mathrm{BB}}=(0.31 \pm 0.07)$ $\mathrm{meV}$. With these results the intercept on the ordinate of figure 3 should be 0.031 mcal mol ${ }^{-1} \mathrm{~K}^{-5 / 2}$ assuming the absence of long-range order of the spins on the octahedral sites.

Kouvel has also provided expressions for the spin-wave heat capacity in the ordered state. As it has been observed that at least the $J_{\mathrm{AB}}$ and $J_{\mathrm{BB}}$ values are almost equal above and below the transition, ${ }^{(94,95)}$ the above values were used in the evaluation which, however, gave the same intercept. Thus, spin-wave contributions of only 40 per cent of the lowest value by Dixon et al. ${ }^{(7)}$ are accounted for by theory. A firm conclusion can be drawn only from measurements at lower temperatures than those reported here.

The continuing support of the Division of Research of the U.S. Atomic Energy Commission is gratefully acknowledged. We also wish to thank Norman E. Levitin for performing most of the heat-capacity measurements, Torkild Thurmann-Moe for assistance in synthesizing the calorimetric sample, and Clinton F. Jefferson for analytical and magnetic moment determinations.

\section{REFERENCES}

1. Parks, G. S.; Kelley, K. K. J. Phys. Chem. 1926, 30, 47.

2. Millar, R. W. J. Amer. Chem. Soc. 1929, 51, 215.

3. Okamura, T. Sci. Repts. Tôhoku Imp. Univ. First Series 1932, 21, 231.

4. Okamura, T.; Torizuka, Y. Sci. Repts. Res. Insts. Tôhoku Univ. 1950, A2, 352.

5. Kouvel, J. S. Phys. Rev. 1956, 102, 1489.

6. Blythe, H.; Harvey, T. J.; Hoare, F. E.; Moody, D. E. Cryogenics 1964, 4, 28.

7. Dixon, M.; Hoare, F. E.; Holden, T. M. Phys. Letters 1965, 14, 184.

8. Calhoun, B. A. Phys. Rev. 1954, 94, 1577.

9. Slack, G. A. Phys. Rev. 1962, 126, 426.

10. Tombs, N. C.; Rooksby, H. P. Acta Cryst. 1951, 4, 474.

11. Abrahams, S. C.; Calhoun, B. A. Acta Cryst. 1955, 8, 257.

12. Basta, E. Z. Mineral Mag. 1957, 31, 431.

13. Swanson, H. E.; McMurdie, H. F.; Morris, M. C.; Evans, E. H. Natl. Bur. Std. (U.S.) Monograph 25, Section 5, Standard X-ray Diffraction Patterns, Washington, D.C. 1967, p. 31.

14. Gorter, E. W. Compt. Rend. 1950, 230, 192; Nature 1950, 165, 798; Thesis, Leiden 1954; Philips Res. Repts. 1954, 9, 295.

15. Weiss, P.; Forrer, R. Ann. phys. 1929, [10] 12, 279.

16. Pauthenet, R. Ann. phys. 1952, [12] 7,710.

17. Westrum, E. F. Jr.; Furukawa, G. T.; McCullough, J. P. In Experimental Thermodynamics, Vol. 1. Editors: J. P. McCullough and D. W. Scott. Butterworths. London. 1968. p. 333.

18. Coughlin, J. P.; King, E. C.; Bonnickson, K. R. J. Amer. Chem. Soc. 1951, 73, 3891.

19. Verwey, E. J. W. Nature 1939, 144, 327; Chem. Weekblad 1942, 39, 30. See also Verwey, E. J. W. : Haayman, P. W. Physica 1941, 8, 979.

20. Sharma, V. N. Phys. Letters 1965, 19, 462.

21. Suiter, W. B. Jr.; Blair, R. J. Appl. Phys. 1965, 36, 1156.

22. Darken, L. S.; Gurry, R. W. J. Amer. Chem. Soc. 1946, 68, 798. 
23. Andersson, S.; Collén, B.; Kuylenstierna, U.; Magnéli, A. Acta Chem. Scand. 1957, 11, 1647.

24. Andersson, S. Acta Chem. Scand. 1954, 8, 1599.

25. Claasen, A. A. Proc. Phys. Soc. (London) 1926, 38, 482; 39, 342.

26. Verwey, E. J. W.; De Boer, J. II. Rec. trav. chim. 1936, 55, 531.

27. Verwey, E. J. W.; Haayman, P. W.; Romeijn, F. C. J. Chem. Phys. 1947, 15, 181.

28. Bickford, L. R., Jr. Phys. Rev. 1949, 75, 1298; 76, 137; 1950, 78, 449.

29. Rooksby, H. P.; Willis, B. T. M. Acta Cryst. 1953, 6, 565.

30. Abrahams, S. C.; Calhoun, B. A. Acta Cryst. 1953, 6, 105.

31. Haas, C. J. Phys. Chem. Solids 1965, 26, 1225.

32. Néel, L. Ann. phys. 1948, [12] 3, 137.

33. Shull, C. G.; Wollan, E. O.; Strauser, W. A. Phys. Rev. 1951, 81, 483; Shull, C. G. Phys. Rev. 1951, 81, 626; Shull, C. G.; Wollan, E. O.; Koehler, W. C. Phys. Rev. 1951, 84, 912.

34. Hamilton, W. C. Phys. Rev. 1958, 110, 1050.

35. Samuelsen, E. J.; Bleeker, E. J.; Dobrzynski, L.; Riste, T. J. Appl. Phys. 1968, 39, 1114. See also Kjeller Report KR-122, October 1967.

36. Wagner, C.; Koch, E. Z. Phys. Chem. 1936, B32, 439.

37. De Bocr, J. H.; Verwey, E. J. W. Proc. Phys. Soc. (London) 1937, 49, 59.

38. Miles, P. A.; Westphal, W. B.; von Hippel, A. Rev. Mod. Phys. 1957, 29, 279.

39. Lavine, J. M. Phys. Rev. 1959, 114, 482.

40. Haubenreisser, W. Phys. Stat. Solidi 1961, 1, 619.

41. Tannhauser, D. S. Phys. Kond. Materie 1964, 3, 146.

42. Adler, D. Rev. Mod. Phys. 1968, 40, 714.

43. Samara, G. A. Phys. Rev. Letters 1968, $21,795$.

44. Zotov, T. D. Fiz. Metal i Metalloved., Akad. Nauk S.S.S.R. 1960, 9, 48; 1959, 8, 639; 1959, $7,906$.

45. Samokhvalov, A. A.; Fakidov, I. G. Fiz. Metal i Metalloved., Akad. Nauk S.S.S.R. 1960, 9, 31; 1959, 8, 694; 1959, 7, 465. See also Davidenko, N. I.; Samokhvalov, A. A.; Fakidov, I. G. Soviet Phys.-Solid State 1961, 3, 1197.

46. Shirakawa, Y. Phys. Rev. 1941, 60, 835.

47. Watanabe, H.; Tsuya, N. Sci. Repts. Res. Insts. Tôhoku Univ. 1950, A2, 29.

48. Okamura, T.; Torizuka, Y.; Kojima, H. Sci. Repts. Res. Insts. Tôhoku Univ. 1949, A1, 479.

49. Li, C. H. Phys. Rev. 1932, 40, 1002.

50. Okamura, T.; Ogawa, S. Proc. Phys.-Math. Soc. Japan 1941, 23, 363; 1943, $25,43$.

51. Domenicali, C. A. Phys. Rev. 1950, 78, 458.

52. Watanabe, H. Sci. Repts. Res. Insts. Tôhoku Univ. 1950, A2, 280.

53. Bickford, L. R., Jr. Rev. Mod. Phys. 1953, 25, 75.

54. Stull, J. L.; Bickford, L. R., Jr. Phys. Rev. 1953, 92, 845.

55. Bickford, L. R., Jr.; Pappis, J.; Stull, J. L. Phys. Rev. 1955, 99, 1210.

56. Williams, H. J.; Bozorth, R. M. Rev. Mod. Phys. 1953, $25,79$.

57. Williams, H. J.; Bozorth, R. M.; Goertz, M. Phys. Rev. 1953, 91, 1107.

58. Narovskaya, N. P. Izvest. Akad. Nauk S.S.S.R. 1958, Ser. Fiz. 22, 1200. See also Kristallografiya 1958, $3,346$.

59. Palmer, W. Phys. Rev. 1963, 131, 1057.

60. Pearson, R. F.; Cooper, R. W. Proc. Phys. Soc. (London) 1961, 78, 17.

61. Yoshida, K.; Tachiki, M. Progr. Theoret. Phys. (Kyoto) 1957, 17, 331.

62. Slonczewski, J. C. J. Appl. Phys. 1961, 32, 2535.

63. Hirone, T.; Watanabe, H.; Mizuno, J.; Tsuya, N. Sci. Repts. Res. Insts. Tôhoku Univ. 1950, A2, 774. See also Okamura, T.; Torizuka, Y. Sci. Repts. Res. Insts. Tôhoku Univ. 1950, A2, $882 ; 1951, A 3,214$.

64. Bonstrom, D. B.; Morrish, A. H.; Watt, L. A. K. J. Appl. Phys. 1961, 32, 2725.

65. Nagamiya, T. Progr. Theoret. Phys. (Japan) 1953, 10, 72.

66. Bickford, L. R., Jr. Phys. Rev. 1953, 92, 845.

67. Ogawa, S.; Morimoto, S. J. Phys. Soc. Japan 1962, 17, 654. See also Ogawa, S.; Morimoto, S.; Kimura, Y.J. Phys. Soc. Japan 1962, 17, 1671.

68. Boyd, E. L. Phys. Rev. 1963, 129, 1961.

69. Callen, E. Phys. Rev. 1966, 150, 367.

70. Solomon, I. Compt. Rend. 1960, 251, 2675.

71. Bauminger, R.; Cohen, S. G.; Marinov, A.; Ofer, S.; Segal, E. Phys. Rev. 1961, 122, 1447.

72. Ito, A.; Ôno, K.; Ishikawa, Y. J. Phys. Soc. Japan 1963, 18, 1465. See also J. Phys. Soc. Japan 1962, 17B, 125 . 
73. Banerjee, S. K.; O'Reilly, W.; Johnson, C. E. J. Appl. Phys. 1967, 38, 1289.

74. Anderson, P. W. Phys. Rev. 1956, 102, 1008.

75. Verwey, E. J. W.; Heilmann, E. L. J. Chem. Phys. 1947, 15, 174.

76. Verwey, E. J. W.; De Bocr, F.; Van Santen, J. I. J. Chem. Phys. 1948, 16, 1091.

77. De Boer, F.; Van Santen, J. H.; Verwey, E. J. W. J. Chem. Phys. 1950,.18, 1032.

78. Van Santen, J. H. Philips Res. Rept. 1950, 5, 282.

79. Matsuura, T.; Yamada, K.; Yoshimori, A. Prog. Theoret. Phys. (Japan) 1966, 36, 679.

80. Pauling, L. The Nature of the Chemical Bond, 3rd ed. Cornell University Press. Ithaca, N.Y. 1960. p. 466.

81. de Bergevin, F.; Brunel, M. Compt. Rend. 1968, 266B, 88.

82. Slater, J. C. J. Chem. Phys. 1941, 9, 16.

83. Kouvel, J. S. Tech. Rept. 210, Cruft Laboratory, Harvard University, Cambridge, Mass. 1955.

84. Pollack, S. R.; Atkins, K. R. Phys. Rev. 1962, 125, 1248.

85. Kaplan, H. Phys. Rev. 1952, 86, 121.

86. Milford, F. J.; Glasser, M. L. Phys. Letters 1962, 2, 248.

87. Glasser, M. L.; Milford, F. J. Phys. Rev. 1963, 130, 1783.

88. Kenan, R. P.; Glasser, M. L.; Milford, F. J. Phys. Rev. 1963, 132, 47.

89. Mills, R. E.; Kenan, R. P.; Milford, F. J. Phys, Rev. 1966, 145, 704.

90. Riste, T.; Blinowski, K.; Janik, J. J. Phys. Chem. Solids 1959, 9, 153.

91. Watanabe, H.; Brockhouse, B. N. Phys. Letters 1962, 2, 248, 1892. See also IAEA Symposium, Inelastic Scattering of Neutrons in Solids and Liquids. IAEA. Vienna. 1963, p. 297 and Phys. Letters 1962, 1, 189.

92. Ferguson, G. A., Jr.; Saenz, A. W. Phys. Rev. 1967, 156, 632.

93. Dimitrijevic, Z.; Krasnicki, S.; Todviovic, J.; Wanic, A. Phys. Stat. Solidi 1967, 22, 155. See also Phys. Stat. Solidi 1966, 15, 119.

94. Alperin, H. A.; Steinsvoll, O.; Nathans, R.; Shirane, G. Phys. Rev. 1967, 154, 508.

95. Torrie, B. H. Sol. State Comm. 1967, 5, 715.

96. Möglestue, K. T. IAEA Symposium on Neutron Inelastic Scattering, Copenhagen, 20-25 May 1968, SM-104/63. 